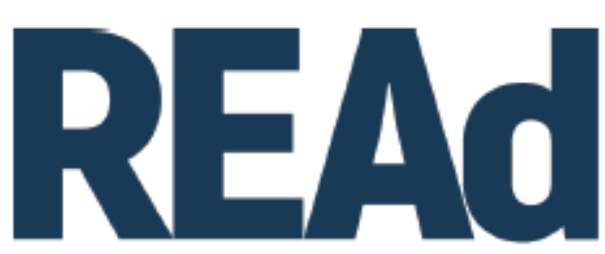

Revista Eletrônica de Administração

\title{
META-ESTUDO CRÍTICO DE PESQUISAS EM ARRANJOS PRODUTIVOS LOCAIS ${ }^{1}$
}

\author{
Joseane Viola Coelho Debortoli ${ }^{2}$ \\ Crystyane Ferreira Bernardino ${ }^{3}$ \\ Uajará Pessoa Araújo ${ }^{4}$ \\ Daniel Paulino Teixeira Lopes ${ }^{5}$
}

http://dx.doi.org/10.1590/1413-2311.300.98171

\section{RESUMO}

Esta pesquisa objetiva analisar a evolução do tema Arranjos Produtivos Locais (APLs) em periódicos brasileiros no período de 1999 a 2018, considerando os principais conhecimentos acumulados. Os APLs constituem uma aglomeração de empresas, desenvolvendo atividades econômicas correlatas e que apresentam vínculos de produção, interação, cooperação e aprendizagem. Com isso, a relevância deste estudo é derivada do conhecimento construído sobre APLs e aponta lacunas que podem induzir novos avanços. A resultante é uma metasíntese que partiu de uma amostra de 325 artigos empíricos e os submeteu às análises sociométricas, bibliométricas e de conteúdo. Encontrou-se um maior aporte em Institucionalismo, Evolucionismo Econômico e Economia Industrial; com poucos casos de triangulação teórica. Foi possível mapear as variáveis, atributos, fatores, construtos e resultados, bem como as suas interações, intervenientes na dinâmica do objeto. Mas persiste a falta de integração do conhecimento gerado pelas pesquisas, capaz de oferecer um modelo mais completo ao entendimento.

\footnotetext{
${ }^{1}$ Recebido em 12/11/2019, aceito em 5/10/2020.

${ }^{2}$ Centro Federal de Educação Tecnológica de Minas Gerais. Programa de Pós-Graduação em Administração; Belo Horizonte - MG (Brasil); http://orcid.org/0000-0003-3601-2305; joseane.viola@ gmail.com.

${ }^{3}$ Centro Federal de Educação Tecnológica de Minas Gerais. Programa de Pós-Graduação em Administração; Belo Horizonte - MG (Brasil); http://orcid.org/0000-0002-3396-1460; crys.ferber@ gmail.com.

${ }^{4}$ Centro Federal de Educação Tecnológica de Minas Gerais. Programa de Pós-Graduação em Administração; Belo Horizonte - MG (Brasil); http://orcid.org/0000-0003-1288-1514; uajara@ gmail.com.

${ }^{5}$ Centro Federal de Educação Tecnológica de Minas Gerais. Programa de Pós-Graduação em Administração; Belo Horizonte - MG (Brasil); http://orcid.org/0000-0001-8928-0245; daniel.lopes@ cefetmg.br.
} 
Palavras-chave: Arranjo Produtivo Local. Produção Acadêmica. Meta-Estudo.

\section{CRITICAL META-STUDY OF LOCAL PRODUCTIVE ARRANGEMENTS RESEARCH}

This research aims to analyze the evolution of the theme Local Productive Arrangements (LPAs) in Brazilian journals from 1999 to 2018, considering the main accumulated knowledge. The LPAs constitute an agglomeration of companies, developing related economic activities and presenting production, interaction, cooperation and learning links. The relevance of the study is derived from the knowledge built on LPAs and points out gaps that can induce new advances. The result is a metasynthesis that started from a sample of 325 empirical articles and submitted them to sociometric, bibliometric and content analyses. A greater contribution was found in Institutionalism, Economic Evolutionism and Industrial Economics; with few cases of theoretical triangulation. It was possible to map the variables, attributes, factors, constructs and results, as well as their interactions, intervening in the dynamics of the object. But there is still a lack of integration of the knowledge generated by research, capable of offering a more complete model to understanding.

Keywords: Local Productive Arrangement. Academic Production. Meta-Study.

\section{META-INVESTIGACIÓN CRÍTICA SOBRE ARREGLOS PRODUCTOS LOCALES}

Esta investigación tiene como objetivo analizar la evolución del tema Arreglos Productivos Locales (APL) en periódicos brasileños en el período de 1999 a 2018, considerando los principales conocimientos acumulados. Los APL constituyen una aglomeración de empresas, desarrollando actividades económicas correlativas y que presentan vínculos de producción, interacción, cooperación y aprendizaje. La relevancia del estudio se deriva del conocimiento construido sobre APL y señala las lagunas que pueden inducir nuevos avances. La resultante es una meta-síntesis que partió de una muestra de 325 artículos empíricos y los sometió a los análisis sociométricos, bibliométricos y de contenido. Se encontró un mayor aporte en Institucionalismo, Evolucionismo Económico y Economía Industrial; con pocos casos de triangulación teórica. Fue posible mapear las variables, atributos, factores, constructos y resultados, así como sus interacciones, participantes en la dinámica del objeto. Pero persiste la 
falta de integración del conocimiento generado por las investigaciones, capaz de ofrecer un modelo más completo al entendimiento.

Palabras clave: Arreglo Productivo Local. Producción Académica. Meta- Investigación.

\section{INTRODUÇÃO}

Os estudos em APLs foram impulsionados principalmente pelas obras de autores clássicos como Marshal (1985) e Porter (1993) e ganharam relevância nos últimos anos, surtindo interesse da academia, governo e indústria (MASCENA; FIGUEIREDO; BOAVENTURA, 2013). Desde então vários autores voltaram-se para a análise interdisciplinar dos APLs, o que contribuiu para enxergar os diversos fenômenos organizacionais presentes nesse cenário.

Há muitas denominações diferentes para o objeto, às vezes denominado arranjo produtivo local, sistema produtivo local ou mesmo cluster. No Brasil a expressão mais usada é Arranjo Produtivo Local - APL.

APLs são aglomerações de empresas, localizadas em um mesmo território, que apresentam especialização produtiva e mantêm vínculos de articulação, interação, cooperação e aprendizagem entre si e com outros atores locais, tais como: governo, associações empresariais, instituições de crédito, ensino e pesquisa (LASTRES; CASSIOLATO, 2003; TEIXEIRA; FERRARO, 2009). Parte-se do pressuposto que, por alguma conjunção de fatores, inclusive históricos, tais atores podem mobilizar-se e, de forma coordenada e continuada, identificar suas demandas coletivas, por iniciativa própria ou por indução de entidades envolvidas com o segmento (ALBINO et al, 2011) e empreender esforços colaborativos continuados.

Porém, não é fácil caracterizar "digitalmente" o que é ou não é um APL: qual montante de vínculos cooperativos habilita um conjunto de agentes com tal rótulo. Talvez, a melhor forma de lidar com o problema é aceitar o recurso analógico: as aglomerações podem estar em diversos estágios de "apelização", desde o status pré-embrionário até o APL pleno ressalvando-se de qualquer determinismo: nem todos atingirão e assim permanecerão no último estágio.

Até mesmo visualizar os limites de um APL é capcioso. Uma empresa que está em um APL, com a mesma especialização produtiva deste, mas que não participa de esforços cooperados de qualquer natureza com os competidores locais, faz parte do APL? Se é mais fácil 
perceber um APL em uma região pequena com alta dependência de renda de uma única atividade que é quase exclusiva no país (caso de APL de fogos de artifício na pequena Santo Antônio dos Montes, MG) como enxergá-lo na região de Divinópolis, cidade de porte médio, também de MG, com seus quatro APL?

Há no país registro oficial de mais de oito centenas de APL tal como mapeados pelo Observatório de APL. Conhecer cada APL pode tornar mais efetivos os recursos empregados, situação reconhecida pela academia, que se debruçou cada vez mais sobre o objeto (MASCENA; FIGUEIREDO; BOAVENTURA, 2013). Dessa forma, o problema de pesquisa que norteia este estudo é: De que modo os estudos em APL estão sendo desenvolvidos e qual o conhecimento acumulado nos artigos publicados em periódicos nacionais no período de 1999 a 2018 ?

Entender o desenrolar dessas pesquisas, pode induzir novos avanços, para além da reprodução do já absorvido. Sendo assim, este artigo objetiva analisar a evolução do tema APL em periódicos brasileiros nos últimos 20 anos, considerando os principais conhecimentos acumulados. A relevância do estudo é derivada do conhecimento construído sobre APLs e aponta lacunas que direcionam caminhos para outros pesquisadores. Percebe-se a contribuição com a geração de novos conhecimentos a partir das fronteiras existentes.

Quando um objeto é suficientemente estudado, há uma expectativa razoável de uma consolidação crítica do entendimento em um "estado da arte” que aprecie o esforço já realizado, aponte as indicações mais aceitas, um denominador comum, conferindo relevância à totalidade, indo além da composição de partes obtidas de mero levantamento descritivo ou sóciobibliométrico; e que, ao mesmo tempo, revele lacunas e aponte novos horizontes de pesquisa. A pretensão é, metaforicamente, descortinar o processo e a parede resultante da conjunção de cada tijolo (pesquisa empírica analisada), habilitando-se para transcendê-la, ao se examinar regularidades, justaposições, amálgamas, inclinações e especificidades. Para dar vazão a essa construção alicerçada em pesquisas originais, há um conjunto de técnicas bem desenvolvidas revisão sistemática, meta-etnografia, meta-narrativa, comparação cruzada de casos, análise secundária de dados primários, análise interpretativa fenomenológica, triangulação ecológica cada uma com seus requisitos, procedimentos e potencialidades (ARAÚJO et al., 2016). Nada impede que um meta-estudo crítico (aqui, basicamente, qualitativo) tome emprestado elementos de mais de uma técnica, desde que elas sejam compatíveis e coerentes entre si, com o objeto em consideração, e com o suporte teórico; com o fito de dar maior extensão as teorias e dados examinados, refiná-los, contrapô-los e recombiná-los, tal qual indicado em Hoon (2013). 
A convergência entre o objeto, o acúmulo ao longo do tempo de conhecimento decorrente de investigações primárias e as possibilidades de síntese (BRANNAN et al., 2017) resultou neste meta-estudo crítico. Tomou-se como "População" as pesquisas que trataram, de forma empírica, seu(s) objeto(s) como APL, disponíveis eletronicamente. Deste conjunto extraiu-se uma amostra, que constituiu o "Corpus" da pesquisa, trabalhados com instrumentos da sócio-bibliometria.

\section{PRISMAS TEÓRICOS DAS PESQUISA SOBRE APL}

No Brasil, percebe-se que as pesquisas sobre APL receberam um crescente interesse no campo acadêmico a partir do início deste século, sendo Farah Júnior (2001) e Cassiolato e Lastres (2001), os autores das obras mais antigas identificadas nas bases pesquisadas. Desde então é notável o grande aumento de artigos em periódicos nos últimos 20 anos, surgindo entre eles alguns estudos bibliométricos sobre o tema.

Santos, Parisoto, Gil e Sghultz (2019) analisaram as publicações cientificas de artigos relacionados ao tema APL no âmbito nacional, de 2008 a 2017, na base de busca Scopus. Os autores verificaram a evolução das publicações nos dez anos e as abordagens utilizadas em cada artigo identificando a inovação e governança como temas centrais das pesquisas em APL. Ouro e Barreto (2014), verificaram, no estudo bibliométrico sobre APL de 2002 a 2012, que muito já foi debatido sobre inovação, competitividade, desenvolvimento local, cooperação e benefícios, todavia ainda faltam artigos que abordem as questões financeiras do APL, exportação, logística e questões que mostrem os fatores que dificultam a continuidade e o desenvolvimento do APL.

Mascena, Figueiredo e Boaventura (2013) exploraram as características das publicações nacionais sobre APL no período de 2000 a 2011. Os resultados encontrados permitiram constatar que muitos estudos analisados restringiram-se a classificar uma aglomeração de empresas de determinada região como clusters ou APLs, do que a identificar seu estágio de desenvolvimento ou a analisar o potencial de determinadas regiões para formação de um APL.

Observa-se o interesse acadêmico nas pesquisas bibliométricas sobre APL e os resultados apontam as características das publicações principalmente quanto às abordagens metodológicas, os autores mais referenciados, os clusters e APL's pesquisados e os temas mais estudados nas publicações nacionais, geralmente no horizonte de 10 anos.

A proposta deste artigo é analisar a evolução do tema APL em 20 anos, considerando os principais conhecimentos acumulados. Esses conhecimentos, além de apontarem as (c) (1) $\Theta$ REAd | Porto Alegre - Vol. 26 - N. 3 - Setembro / Dezembro 2020 - p. 709-738. 
abordagens metodológicas, autores, e temas estudados, têm a pretensão de refletir sobre a evolução dos estudos e apontar também as perspectivas teóricas das pesquisas em APL de acordo com Corpus, como mostra o Quadro 1.

O modo como diversas perspectivas teóricas têm sido utilizadas para se analisar o campo dos Arranjos Produtivos Locais enriquece o entendimento que se tem do assunto. A triangulação teórica permite que os dados sejam abordados utilizando-se perspectivas teóricas e hipóteses múltiplas, frequentemente apropriando-se de modelos teóricos de outras disciplinas para explicar a realidade, onde os dados que refutariam hipóteses centrais poderiam ser coletados e colocados lado a lado com vários pontos de vista (DENZIN, 1970). Assim, pesquisadores com diferentes bagagens teóricas e áreas de conhecimento trabalham em conjunto para analisar a mesma questão de pesquisa (GUION, 2002).

O Quadro 1 retrata o resultado de um esforço de tipificação teórica das pesquisas do Corpus, com uma breve apresentação delas e de seus autores de destaque. Enquanto seria razoável esperar que a classificação fosse imediata, em decorrência de uma autodeclaração explícita no texto, ela requereu, em um volume considerável de casos, uma análise mais minuciosa do texto e utilização de fontes (entre elas, de autores seminais de cada abordagem) para o enquadramento (com algum grau de subjetividade por parte dos analistas) nas vezes em que a indicação não se fazia presente.

A última coluna do Quadro 1 apresenta a frequência com que as teorias foram efetivamente aplicadas às pesquisas do Corpus. É adequado destacar que algumas pesquisas utilizaram-se de mais de uma perspectiva teórica, que outras dispensaram-se de maior embasamento teórico e que o Quadro 1 apresenta apenas aquelas mais frequentes.

Quadro 1 - Perspectivas teóricas em pesquisas em APL em acordo com o Corpus.

\begin{tabular}{|l|l|l|c|}
\hline \multicolumn{1}{|c|}{$\begin{array}{c}\text { Perspectiva } \\
\text { Teórica }\end{array}$} & \multicolumn{1}{|c|}{ Conceito } & \multicolumn{1}{|c|}{ Principais referências } & $\begin{array}{c}\text { Frequência absoluta } \\
\text { das teorias no Corpus }\end{array}$ \\
\hline Institucionalismo & $\begin{array}{l}\text { Examina como as pressões externas } \\
\text { influenciam as ações } \\
\text { organizacionais e como o ambiente } \\
\text { institucional conduz o } \\
\text { estabelecimento e a difusão de } \\
\text { normas de atuação, necessárias ao } \\
\text { alcance da legitimidade } \\
\text { organizacional, através de } \\
\text { processos isomórficos. }\end{array}$ & $\begin{array}{l}\text { DiMagio e Powell } \\
\text { Scott (1995), } \\
\text { Machado-da-Silva e } \\
\text { Fonseca (1996). }\end{array}$ & 79 \\
\hline $\begin{array}{l}\text { Enalisa o processo de evolução das } \\
\text { Econômico }\end{array}$ & $\begin{array}{l}\text { empresas frente ao mercado e o } \\
\text { desaparecimento das que não se } \\
\text { adaptam. }\end{array}$ & $\begin{array}{l}\text { Schumpeter (1988), } \\
\text { Lundson e Winter (1982), }\end{array}$ & 69 \\
\hline $\begin{array}{l}\text { Economiall (1998). } \\
\text { Industrial e Teoria }\end{array}$ & $\begin{array}{l}\text { Busca métodos para entender a } \\
\text { natureza e funcionamento das }\end{array}$ & $\begin{array}{l}\text { Scherer e Ross (1990), } \\
\text { Williamson (1990), }\end{array}$ & 63 \\
\hline
\end{tabular}




\begin{tabular}{|c|c|c|c|}
\hline $\begin{array}{l}\text { do Custo de } \\
\text { Transação }\end{array}$ & $\begin{array}{l}\text { empresas, dos mecanismos de } \\
\text { coordenação de suas atividades e de } \\
\text { seus mercados. } \\
\text { Permite analisar em que } \\
\text { circunstâncias os movimentos de } \\
\text { integração vertical, bem como a } \\
\text { realização de contratos geram } \\
\text { ganhos de eficiência. }\end{array}$ & Barney e Hansen (1994). & \\
\hline Teoria de Redes & $\begin{array}{l}\text { Adota como princípio que as } \\
\text { ligações entre pessoas são } \\
\text { importantes porque elas transmitem } \\
\text { comportamento, atitudes, } \\
\text { informações e mercadorias; analisa } \\
\text { estas ligações e seus indicadores. }\end{array}$ & $\begin{array}{l}\text { Burt (1992), } \\
\text { Granovetter (1983), } \\
\text { Borgatti (2013). }\end{array}$ & 35 \\
\hline $\begin{array}{l}\text { Dependência de } \\
\text { Recursos }\end{array}$ & $\begin{array}{l}\text { Volta-se para a capacidade } \\
\text { organizacional em obter recursos } \\
\text { vitais, a negociação e o } \\
\text { relacionamento interorganizacional } \\
\text { como básico para a sobrevivência }\end{array}$ & $\begin{array}{l}\text { Aldrich e Pfeffer (1976), } \\
\text { Tobert (1985), } \\
\text { Rossetto e Rossetto (2005) }\end{array}$ & 8 \\
\hline Negociação & $\begin{array}{l}\text { Trata da utilização da informação e } \\
\text { do poder para influenciar certo } \\
\text { comportamento em uma rede de } \\
\text { tensão. }\end{array}$ & $\begin{array}{l}\text { Cohen (1980) } \\
\text { Fischer e Ury (1981) } \\
\text { Mills (1993) }\end{array}$ & 7 \\
\hline $\begin{array}{l}\text { Visão Baseada em } \\
\text { Recursos }\end{array}$ & $\begin{array}{l}\text { Considera as competências, } \\
\text { capacidades e as habilidades como } \\
\text { bases do conhecimento fonte de } \\
\text { vantagem competitiva e da } \\
\text { lucratividade das firmas. }\end{array}$ & $\begin{array}{l}\text { Penrose (1959), } \\
\text { Demsetz (1973), } \\
\text { Foss (1993). }\end{array}$ & 6 \\
\hline
\end{tabular}

Diferentes lentes teóricas são tomadas para se validar ou ampliar as interpretações feitas pelo pesquisador. Isso significa assumir visões distintas a respeito do problema de pesquisa, combinando-se diferentes tipos de dados sob as abordagens teóricas e produzindo-se conhecimento além do que seria possível adotando-se uma única perspectiva (FLICK, 2008).

Stake (2011) discute que na triangulação são adotadas diferentes percepções para se esclarecer significados por meio da repetição das observações ou interpretações. No entanto, sabendo-se que nenhuma observação ou interpretação se repete perfeitamente, a triangulação também serve para elucidar significados pela identificação das diferentes maneiras pelas quais um caso é visto.

Dentre as teorias organizacionais, no estudo de APLs o mainstream é formado pelas teorias citadas no Quadro 01, em sua expressiva maioria. Interações entre teorias como Institucionalismo e Evolucionismo Econômico, ou Economia Industrial e Redes, Negociação e teoria dos Stackeholders, Redes e Ecologia Organizacional, Economia Industrial e Evolucionismo Econômico puderam ser vistas nos artigos analisados por esta bibliometria. E dentre estas, algumas perspectivas teóricas ainda se sobressaem às outras, quanto à sua utilização para se explicar o fenômeno. 


\section{PROCEDIMENTOS METODOLÓGICOS}

Este meta-estudo crítico partiu, inicialmente, de uma pesquisa bibliométrica que, segundo Okubo (1997), examina a produção de artigos em um determinado campo de saber, mapeia as comunidades acadêmicas e identifica as redes de pesquisadores e suas motivações. Tais objetivos são tangibilizados por meio da criação de indicadores que buscam sumarizar as instituições e os autores mais prolíferos, os acadêmicos mais citados e as redes de coautorias.

De posse dos principais achados teóricos e empíricos dessa fase inicial, buscou-se integrar e sintetizar os resultados no que chamamos "meta-estudo crítico", numa aproximação ao que Brannan et al. (2017) denominaram síntese realista crítica. Para os autores, o objetivo das ciências sociais não é prever, mas explicar os fenômenos envolvendo agentes, mecanismos causais, tendências, resultados e contextos.

Desta forma, foram definidas cinco categorias de análise usadas para interpretar os dados. São elas: Cooperação, Governança, Rede, Inovação e Política Pública. Bardin (2004) argumenta que as categorias de análise podem ocorrer com base nos conceitos do referencial teórico ou a partir das verbalizações referentes aos temas, devendo ser apresentadas claramente. Assim, buscou-se compreender a dinâmica das pesquisas em APL ao longo do tempo em meio as proposições decorrentes das análises efetuadas neste meta-estudo crítico.

\subsection{A CONSTRUÇÃO DO CORPUS}

Em setembro de 2018, foi feita a pesquisa inicial no Google Scholar ${ }^{6}$ empregando os descritores "arranjos produtivos locais", "arranjo produtivo local" e "aglomeração produtiva local" para o período de 1999 a 2018, abrangendo assim um horizonte de 20 anos, decomposto em tercis (até 2009, de 2010 a 2014 e de 2015 em diante, cada um com aproximadamente 5 mil entradas recuperadas) ${ }^{7}$. De cada tercil, foram extraídos os primeiros 200 trabalhos empíricos publicados em periódicos indicados pela ferramenta de busca. A seguir, foram excluídas as entradas múltiplas do mesmo artigo e eliminados erros na primeira classificação. Ao final,

\footnotetext{
${ }^{6}$ A opção pelo Google Scholar deveu-se a um teste preliminar considerando facilidade operacional e grau de recuperação, também atentando-se para o escopo proposto: artigos em periódicos nacionais, que eliminou bancos de monografias e tornou menos interessantes as plataformas internacionais. Essa base, portanto, se mostra mais inclusiva para periódicos brasileiros.

${ }^{7}$ Participaram da coleta inicial de dados: SILVA, Daniel Rocha; DO CARMO, Francisco Mendes; SCHREIBER, Franz Campagnacci.
} 
gerou-se um banco de dados com $325 \operatorname{artigos}^{8}$ que foram recuperados em sua integra para compor o Corpus da pesquisa.

O algoritmo do buscador, além de oferecer os resultados mais próximos às expressões de busca, também retorna os trabalhos mais citados, eventualmente, mais expressivos. Desta forma, a definição da quantidade (200) foi decorrência de ter-se optado por trabalhar com um corpus mínimo de 300 artigos, dentro da faixa mais costumaz para trabalhos cientométricos (ARAÚJO, et al. 2017). A Figura 1 apresenta a acumulação das pesquisas na População e no Corpus. O procedimento reportado propiciou uma razoável proporcionalidade entre a População (15.264 itens, escala à esquerda) e o Corpus (325 artigos, escala a direita) ao longo do tempo, como indicado pelo $\mathrm{R}^{2}$ de 0,74 , representado na janela da esquerda superior da Figura 1. O maior descasamento foi observado entre 2012 e 2014, período que ficou sub-representado no Corpus. Trata-se de uma boa amostra, mas, assumidamente, não estatística: além da subrepresentação, o algoritmo do Google Scholar favorece os trabalhos mais citados entre aqueles com maior aderência ao termo de busca: os itens não tiveram igual chance de compor a amostra.

Figura 1- Relação ao longo do tempo entre a População e o Corpus

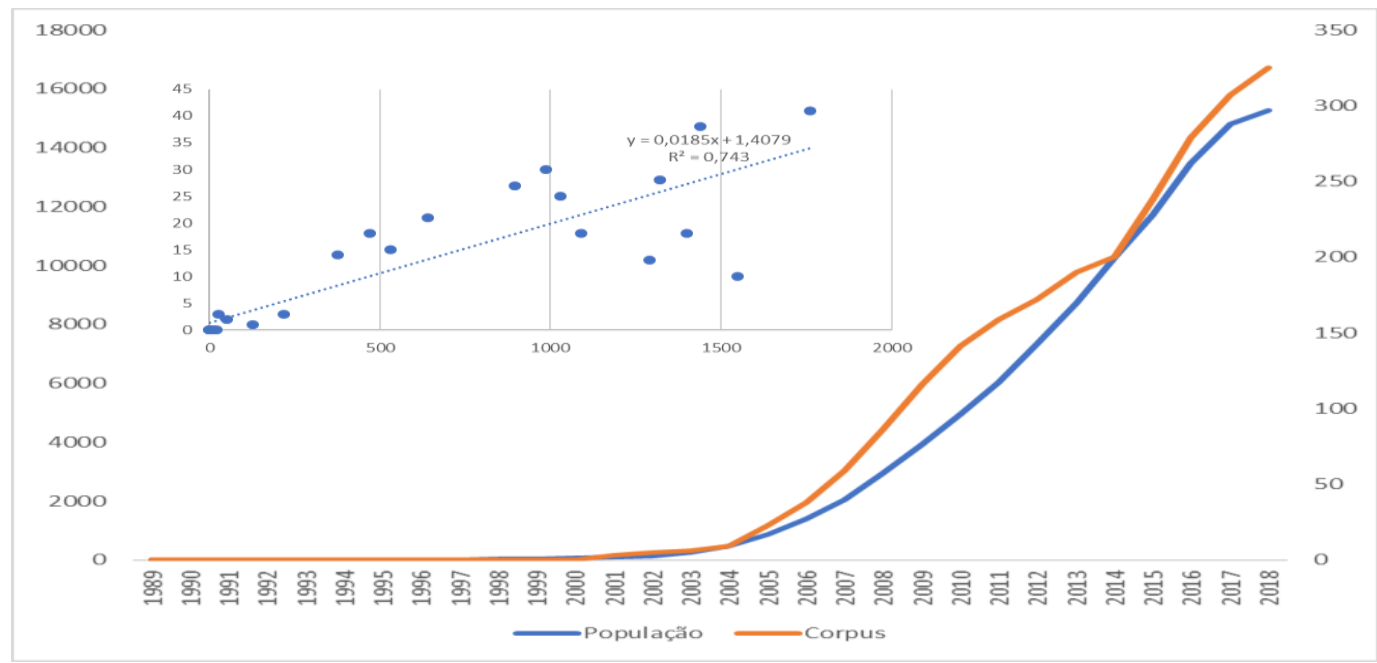

A curva da População é aquela esperada para a difusão de uma inovação (no caso, pesquisa sobre APL), tal como predito no modelo de Rogers (1983), caracterizado por uma curva em "S", com três taxas de acúmulo distinta ao longo do tempo (lento, inicialmente; acelerado, a partir de um momento; culminando, com o decréscimo da taxa, quando o campo dá sinais de saturação). No caso, ainda se estaria no segundo momento.

\footnotetext{
${ }^{8}$ Base de dados: (https://drive.google.com/file/d/). 


\section{RESULTADOS DA PESQUISA}

A análise bibliométrica dos 325 artigos pesquisados resultou nas descobertas abaixo que foram divididas em publicações por ano, área de conhecimento, teorias utilizadas, Qualis, principais periódicos, abordagens metodológicas, autoria e coautoria.

Assim, aplicando a cientometria aos metadados do Corpus, revelam-se:

i. As áreas do conhecimento que se debruçaram sobre os APLs foram: Administração (240 artigos publicados dos 325 analisados), Interdisciplinar (29), Planejamento Urbano (27) e Economia (18). Além dessas, foram encontrados trabalhos em outras oito áreas.

ii. Tomando como referência o maior Qualis do periódico, os trabalhos foram publicados em revistas de Qualis A1 (1 artigo), A2 (20), B1 (86), B2 (63), B3 (75), B4 (54), B5 (23) e $\mathrm{C}$ (3); total de 13.570 pontos, para $\mathrm{A} 1=100, \mathrm{~A} 2=80, \mathrm{~B} 1=60, \mathrm{~B} 2=50, \mathrm{~B} 3=$ 30, B4 = 20, B5 = 10, e C = 0 (critério da área de Administração). Portanto, uma "pontuação média" de 42 pontos, o que colocaria a produção "média" em um estágio entre B2 e B3, daí, qualidade mediana - apenas 1 em cada 3 trabalhos foi publicado em periódicos tidos de melhor qualidade (Qualis A1, A2 e B1).

iii. Houve uma concentração reveladora da preferência dos pesquisadores frente aos periódicos. Dentre as centenas de veículos à disposição, algumas revistas acabaram (por vocação ou outro motivo) por se destacar em APL. É o caso de Revista Brasileira de Gestão e Desenvolvimento Regional (20 dos 325 artigos); Redes Desenvolvimento Regional (9); Interações - Revista Internacional de Desenvolvimento Local (8); Revista Espácios (7); Revista Paranaense de Desenvolvimento (7). Outros 215 periódicos apareceram na relação.

iv. Ocorreram 832 participações de 612 pesquisadores, uma média de 1,3 participações por autor; sendo que o autor mais destacado participou de nove artigos, apenas cinco pessoas ( $0,8 \%$ dos autores) tiveram cinco ou mais participações e a maioria (455, portanto $74,3 \%$ dos autores) teve apenas uma participação. Trata-se de uma distribuição, com poucos autores com muitas participações e muitos autores com apenas uma participação. Adicionalmente, se é possível falar em uma "elite" de pesquisadores, considerando-a como composta de autores com 3 ou mais participações, essa alcançaria 39 pesquisadores, que respondem por apenas $6,4 \%$ das participações.

v. Até 2015, inclusive, a média de autores por artigo foi de 2,4. A partir daí, os trabalhos mais recentes passaram a contar com 3,0 autores, em média - aumentando-se 
significativamente a frequência de artigos com 4 ou 5 autores. Essa propensão de aumento das parcerias parece que é recorrente em pesquisas bibliométricas no país.

vi. Como o período de 20 anos é longo e pesquisadores podem não estar mais ativos no campo, quer por novos interesses ou por aposentadoria, para análise da rede de pesquisadores foram apurados os indicadores e testaram as proposições sociométricas em três intervalos: 2001 a 2006; 2007 a 2012; e mais recente, 2013 a 2018; e, a título mais informativo, 2001 a 2018.

A Tabela 1 apresenta as indicações sociométricas mais relevantes das redes consideradas.

Tabela 1 - Indicações sociométricas

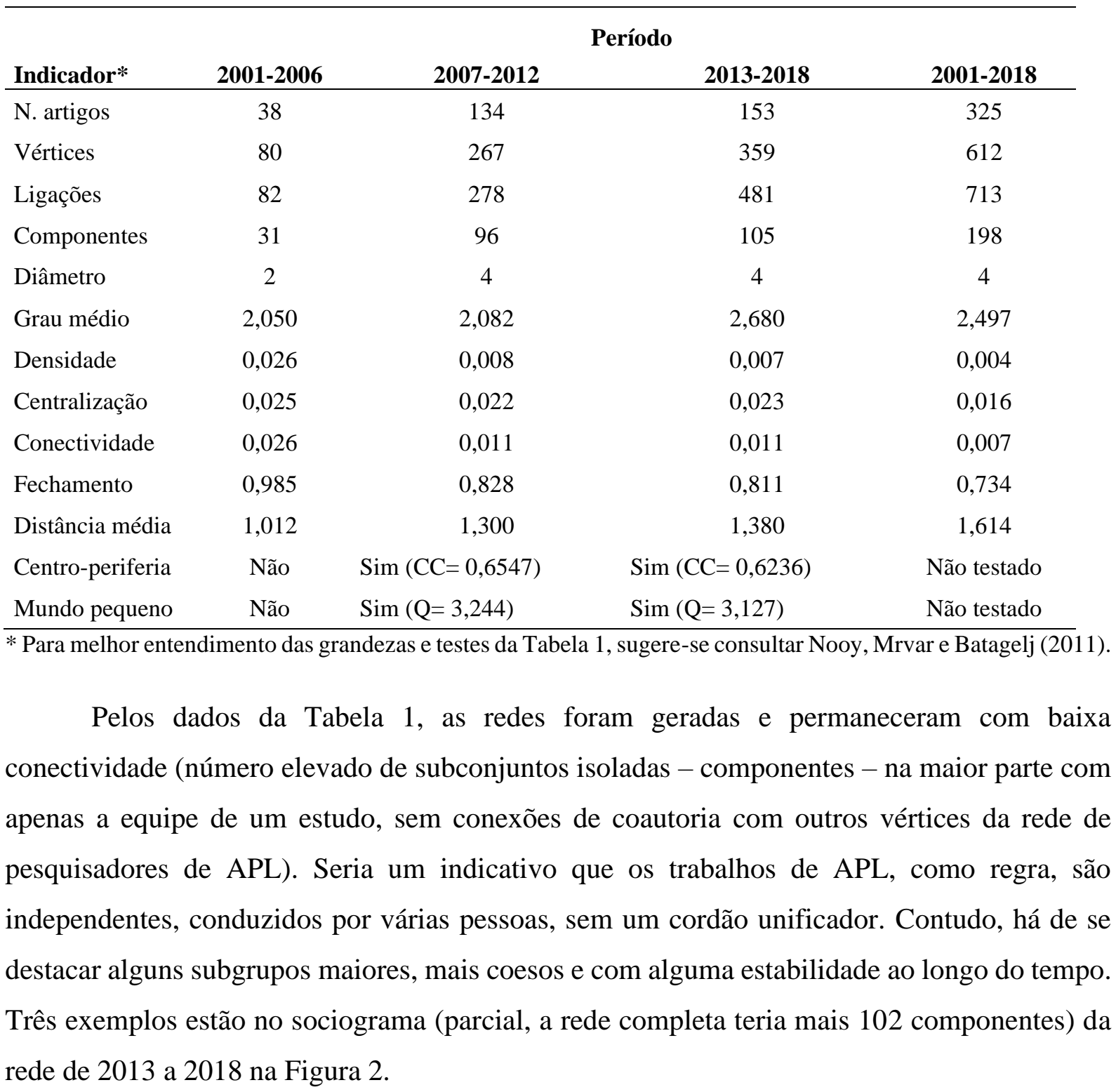

Figura 2 - Maiores componentes, 2013 a 2018 


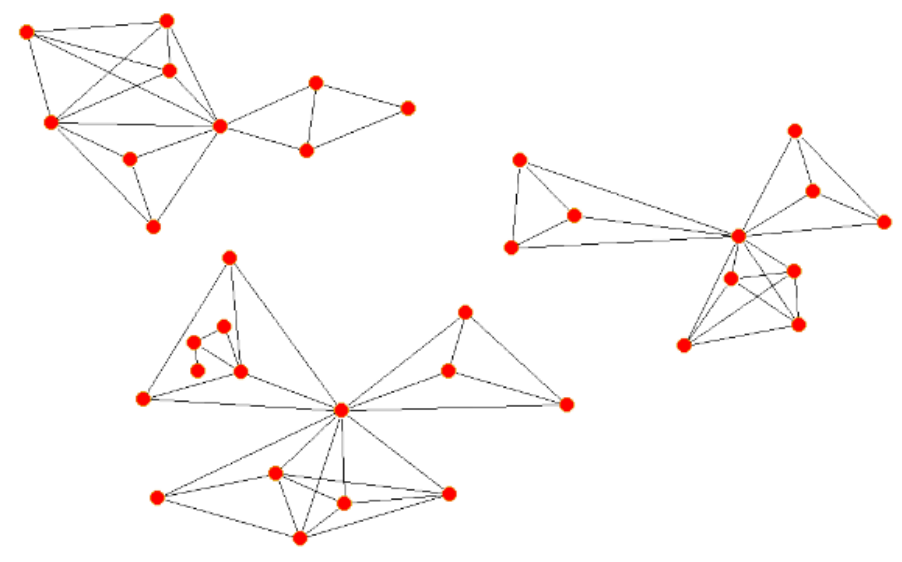

Fonte: dados da pesquisa

O maior componente (nomeado: UFLA), que aparece na parte inferior da Figura 2, tem apenas 15 autores e 29 ligações. O que caracteriza todos esses subgrupos é a evidência de um elemento central que responde, em maior monta, pela conectividade estrutural. No caso, o componente UFLA, é centrado no professor Bruno Tavares, que pesquisa APL desde 2011, junto com seu colega Luiz Marcelo Antonialli e seus orientandos, como Cleber Carvalho Castro e Carla Cristina da Silva, todos do Programa de Pós-Graduação em Administração da UFLA. Os dois outros componentes destacados pela Figura 2 são centrados em Paulo Cruz Correia (UNESPAR) e em Márcio Jacometti (UTFPR).

Já avançando para o conteúdo dos trabalhos recepcionados no Corpus, destacam-se alguns pontos metodológicos:

vii. Óbvio, o objeto básico das pesquisas é o APL. É de todo necessário caracterizar o conjunto quanto aos APL estudados. A forma escolhida foi distribuir os APL em função da atividade econômica, utilizando o CNAE. O resultado está na Tabela 2.

Tabela 2 - Distribuição dos APL estudados por atividade econômica

\begin{tabular}{llr}
\hline SEÇÃO & DIVISÃO & $\mathrm{n}$ \\
\hline $\begin{array}{l}\text { Agricultura, pecuária, } \\
\text { florestal, pesca ... (50) }\end{array}$ & 01 Agricultura, pecuária e serviços relacionados & 38 \\
Indústrias extrativas... (12) & Outras & 12 \\
& 08 Extração de minerais não-metálicos & 5 \\
& Outras & 7 \\
Indústrias de transformação... & 13 Fabricação de produtos têxteis & 23 \\
(191) & 14 Confecção de artigos do vestuário e acessórios & 51 \\
& 15 Preparação de couros e fabricação de artefatos de couro ... & 24 \\
& 20 Fabricação de produtos químicos & 6 \\
& 21 Fabricação de produtos farmoquímicos e farmacêuticos & 6 \\
& 23 Fabricação de produtos de minerais não-metálicos & 12 \\
& 26 Fabricação de equipamentos de informática, eletrônicos e... & 7 \\
& 28 Fabricação de máquinas e equipamentos & 8
\end{tabular}




\begin{tabular}{llr}
$\begin{array}{l}\text { Comércio; reparação de } \\
\text { veículos ... (9) }\end{array}$ & 47 Comércio varejista & 8 \\
& Outras & 1 \\
$\begin{array}{l}\text { Informação e comunicação ... } \\
(37)\end{array}$ & 62 Atividades dos serviços de tecnologia da informação & 34 \\
Atividades administrativas ... & Outras & 3 \\
$(24)$ & Outras Agências de viagens, operadores turísticos e ... & 20 \\
Outras seções ... (7) & Outras & 4 \\
\hline
\end{tabular}

Pela Tabela 2, a pesquisa de APL alcançou diversas seções do CNAE. Mas há uma concentração evidente na área de têxteis e vestuário (74 pesquisas); de informática, tecnologia da informação e eletrônicos (44); de agricultura, pecuária e serviços relacionados (38) e fabricação de móveis (33). Vale conferir destaque em serviço às pesquisas com APL relacionadas a turismo (20). Daí, duas em três pesquisas estudam APL destas cinco áreas destacadas. Quando comparado com a listagem do Observatório de APL, há uma razoável concordância entre áreas pesquisadas e áreas de atuação dos 770 APL registrados no Observatório, com a exceção da agricultura, pecuária e pesca, que ficou sub-representada no Corpus (no Observatório, é a área com mais APL).

Mas o mesmo não pode ser dito em relação à dispersão geográfica dos APL e das pesquisas de APL. A correlação é muito fraca $\left(R^{2}=0,23\right)$ : estados como Rio Grande do Norte, com 87 APL reconhecidos pelo Observatório de APL atraiu apenas duas pesquisas; enquanto, por exemplo, o Paraná, com 30 APL, atraiu 57 pesquisas. Há a maior concentração de pesquisas em estados do sul e do sudeste, onde também se concentram os cursos de Pós-Graduação. Parece razoável conjecturar que a "conveniência" exerce papel relevante na escolha do objeto, ao invés de critérios com tipicidade (representante de uma fração considerável da população) / atipicidade (maior, menor, mais efetivo, mais antigo ou outro ponto de destaque).

Cabe destacar a concentração de interesses em alguns APL, como de Ubá/MG (móveis) e de Santa Rita do Sapucaí/MG (eletrônicos) e regiões, como Belo Horizonte/MG (biotecnologia e software), Campina Grande/PE (calçados, comércio, produtos têxteis, vestuário e eventos) e Sudoeste do Paraná (móveis, software e vestuário) - todos com sete ou mais pesquisas.

viii. A maioria absoluta (91\%) das pesquisas assumiu o corte temporal transversal, um retrato da situação. Isso pode ser entendido como uma restrição, na medida em que a situação atual de um APL decorre de sua trajetória histórica: um filme seria mais esclarecedor da dinâmica. Mas o corte temporal depende dos objetivos e métodos 
estabelecidos pelos pesquisadores e, eventualmente, exigiria deles um comprometimento longo nem sempre compatível, por exemplo, com os prazos de mestrado e doutorado que podem ensejar investigações tendo APL como objeto.

ix. Sem surpresa, 245 artigos utilizaram o método de estudo de caso, em acordo com Gil (2002) que afirma que o método de estudo de caso é a modalidade de pesquisa mais utilizada nas ciências sociais.

x. Em autodeclaração, $78 \%$ se definiram como estudos descritivos. Apenas um a cada 16 artigos teve pretensões explicativas (meros $6 \%$ do Corpus $=20$ trabalhos), de avançar na relação causa-efeito. A opção descritiva é de menor risco e não demanda uma abordagem quantitativa e objetivista, típica de pesquisas explicativas, ainda mais quando se pretende testar hipóteses e/ou modelos.

xi. Apenas $11 \%$ das pesquisas triangularam métodos qualitativos e quantitativos. Técnicas qualitativas foram favorecidas (63\% do Corpus).

xii. Entrevistas (em 89 trabalhos) e questionários (em 70) foram os instrumentos de coleta de dados preferidos. Em segundo plano, lançou-se mão de observação e de documentos.

xiii. Os dados qualitativos foram submetidos, como regra, à análise de conteúdo. A análise de discurso foi empregada em somente cinco trabalhos.

xiv. Além das estatísticas descritivas convencionais, foram encontrados trabalhos que processaram seus dados quantitativos através de: análise fatorial, análise inferencial dos dados, estatística não paramétrica, método de dados em painel com estimação de efeitos fixo, método de diferenças-em-diferenças e o teste de Mann-Whitney.

xv. A boa prática de relatar a pesquisa na área das Ciências Sociais Aplicadas recomenda a explicitação da fundamentação teórica, apontando o prisma a que o fenômeno foi submetido. Nem sempre isso foi observado no Corpus. Nessas insuficiências, houve a necessidade de inferência pela análise do artigo e das referências empregadas, implicando em um certo grau de arbitrariedade. $\mathrm{O}$ melhor que se pôde fazer conduziu à definição de quatro blocos: (a) Recorrentes: institucionalismo, evolucionismo econômico e economia industrial (usadas cada uma em torno de 70 trabalhos); (b) Frequentes: teoria de redes e o que se denominou perspectiva gerencial (em torno de 30 trabalhos); (c) Raras: teoria da dependência de recursos, teoria dos custos de transação, negociação, e visão baseada em recurso (em 8 pesquisas); (d) Exceções: ecologia organizacional, comunicação, marxismo, teoria dos stakeholders, teoria dos espaços, teoria dos sistemas, gestão do conhecimento e estratégia. 
Observa-se que as pesquisas de APL no Corpus usaram mais de 8,4 mil citações, em uma média de 26 referências por trabalho, com considerável dispersão (encontrou-se trabalho com apenas duas referências; e outro artigo, com 85 fontes citadas, caso bem atípico). Uma constatação interessante está em que apenas 61 fontes foram citadas em dez ou mais trabalhos, sendo que 3.134 foram citadas apenas em um único artigo. Por outro lado, duas referências apareceram em 86 artigos. A Figura 3 apresenta a situação, onde a abcissa indica o logaritmo na base 10 do número de vezes (de 1 a 86) que as obras foram citadas; e a ordenada, por sua vez, indica, também na mesma escala logarítmica, a frequência (de 3.134 a 1) com que aquele número de vezes ocorreu.

Figura 3 - Distribuição das fontes entre os trabalhos do Corpus

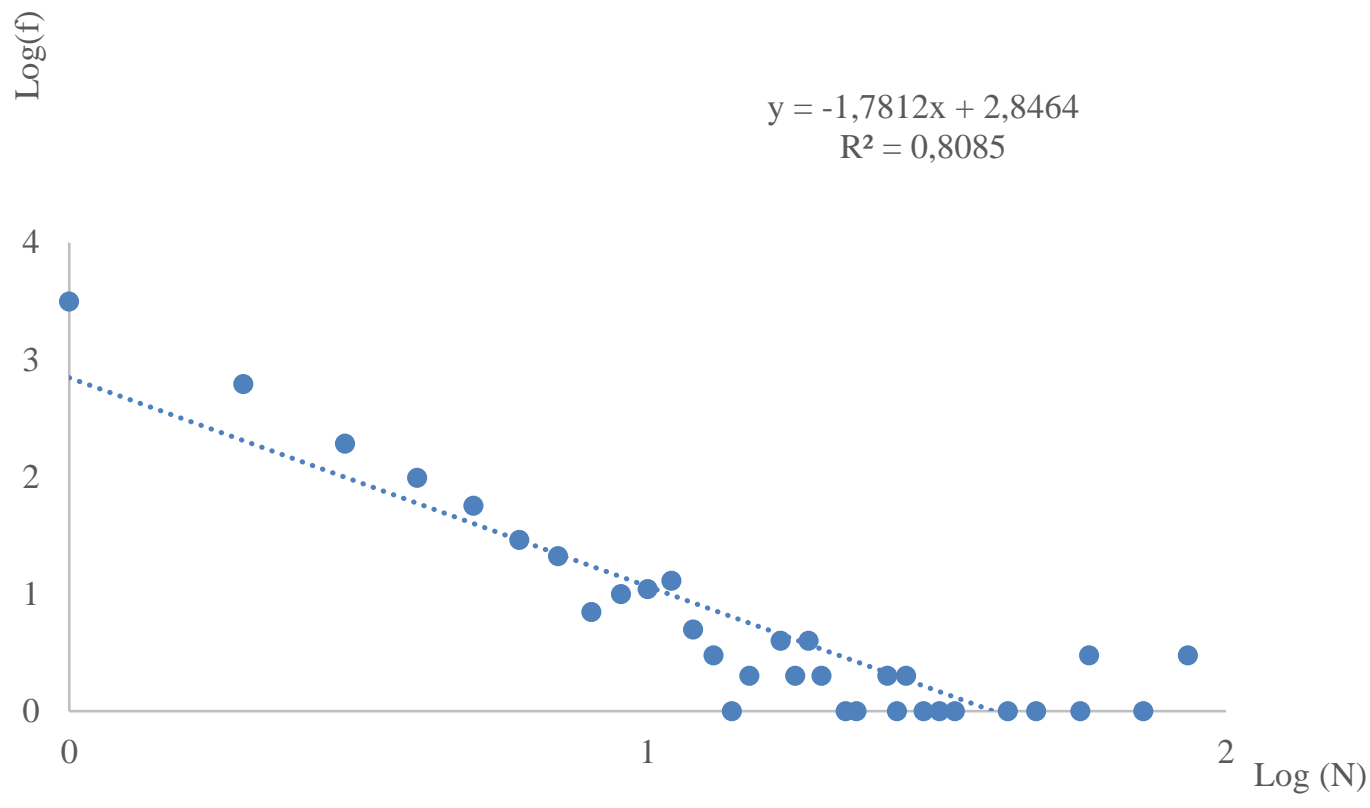

Algumas das fontes mais populares, excluindo banco de dados, autores pessoa jurídica (SEBRAE, IPARD, por exemplo) e manuais de metodologia, foram:

- Marshall (1985). "Princípios de economia", em 72 artigos;

- Cassiolato e Lastres (2003). “O foco em arranjos produtivos e inovativos locais de micro e pequenas empresas", em 56 artigos;

- Porter (1998). “Clusters and the new economics of competition”, em 47 artigos;

- Amato Neto (2000). "Redes de cooperação produtiva e clusters regionais: oportunidades para as pequenas e médias empresas", em 34 artigos; 
- Suzigan et al. (2004). "Clusters ou sistemas locais de produção: mapeamento, tipologia e sugestões de políticas", em 32 artigos;

- Lastres e Cassiolato (2003). "Glossário de arranjos de sistemas produtivos e inovativos locais", em 30 artigos;

- Castells (1999). “A sociedade em rede”, em 28 artigos;

- Casarotto Filho e Pires (2001). "Redes de pequenas e médias empresas e desenvolvimento local", em 27 artigos.

Basicamente, tais fontes se prestam sobretudo para caracterizar o tema do trabalho, não estando entre aquelas (a exceção de Porter e Marshall) que possam ser consideradas "seminais". Apenas como sinalização, dois expoentes da teoria de rede, Granovetter e Burt, tiveram suas obras citadas 12 e 4 vezes, respectivamente; do institucionalismo, Scott e DiMaggio, 7 e 9; da dependência de recursos, Pfeffer apareceu uma única vez; melhor sorte teve Lundvall (diversas obras), do evolucionismo histórico, que foi citado em 52 oportunidades.

Com tais indicações, ao frequentemente dispensar os clássicos, torna-se razoável, de pouco risco, apontar que o "aproveitamento" de trabalhos seminais e, em consequência, a triangulação teórica mais rigorosa, não é prática habitual dos pesquisadores de APL, o que pode ter afetação negativa no resultado dos trabalhos.

\section{ACHADOS DAS PESQUISAS DO CORPUS}

As melhores formas encontradas para compilar os achados (proposições decorrentes das análises efetuadas) foram: (i) analisar as representações gráficas dos termos constantes dos objetivos e das conclusões (nuvens de palavras), buscando compreender a dinâmica das pesquisas ao longo do tempo; e (ii), fazer um exercício de usar o Corpus para compor as indicações de causas de sucesso e insucesso de um APL.

\section{Dinâmica dos pontos focais (PF)}

A figura 4 dá destaque aos termos mais relevantes (pontos focais - PF) nos períodos de 2001 a 2009 (111 artigos), 2010 a 2015 (122 artigos), e 2016 a 2018 (92 artigos), respectivamente. A separação dos períodos foi no sentido de dividir o Corpus de forma mais equilibrada quanto ao número de trabalhos. É razoável afiançar que ao longo do tempo, para a mesma categoria de objeto de pesquisa (APL), o foco dos pesquisadores foi sendo alterado. 
- Alguns PF, mesmo já presentes nos primeiros artigos, foram gradativamente tornandose mais relevantes e centrais, como o caso da Governança e da Inovação (essa, quase imperceptível até 2009).

- Outros PF, já presentes inicialmente, tornaram-se centrais, para depois esvaziar-se, como no caso de Redes.

- Existem PF, destacando Cooperação e Política(s) que vão sendo gradativamente abandonados.

- PF como Coopetição ainda não aparecem (até a data) como centro de atenção.

- Confiança, Reciprocidade, Coesão, Controle (social) - alicerces para a cooperação são tão secundários que não aparecem ou se apresentam em tamanho reduzido.

- PF como Recursos, Oportunismo, Competência e Legitimação/Legitimidade onipresentes em discursões calcadas nas Teorias da Dependência de Recursos, dos Custo das Transações, da Visão Baseado em Recursos e do Institucionalismo quando muito, são secundários.

Figura 4 - Nuvem de palavras
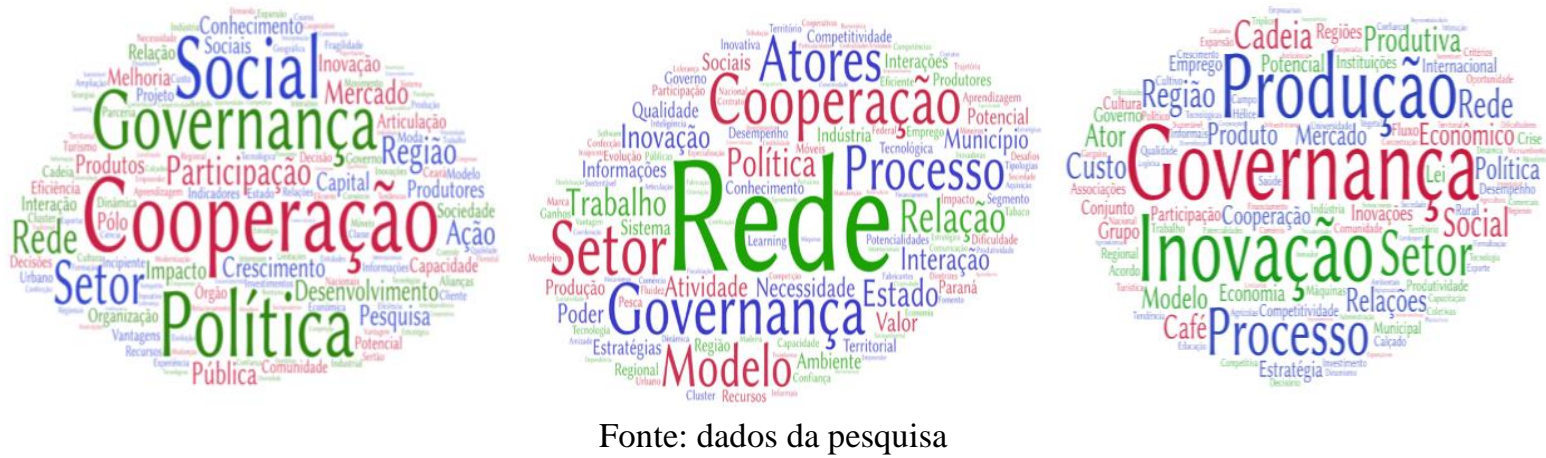

A seguir é feito um resumo dos achados relacionados aos PF que se destacaram. Esse compilado se fez analisando as conclusões dos 325 artigos do Corpus, sintetizando os achados que se repetiam e destacando os divergentes.

\section{Cooperação}

O PF Cooperação traz a discussão principal sobre a necessidade das empresas que compõem os APL atuarem de modo conjunto e integrado, como forma de fortalecerem-se, incorporando princípios que ultrapassem o limite da esfera econômica. Seria necessário empreender esforços concentrados, contínuos e duradouros para a constituição de redes de cooperação como forma de promover a sustentabilidade corporativa pela via da coopetição (cooperação e competição entre entidades empresariais de uma mesma indústria). 


\section{Governança}

Aprende-se do Corpus, que a Governança em APL pode ser entendida como uma articulação capaz de definir e assegurar a observância de regras; amealhar recursos e distribuir benefícios de forma aceitável; estimular o fluxo de informação e de conhecimento; desenvolver oportunidades de ações cooperadas; administrar conflitos; e fazer a representação política. Pode ser exercida por uma liderança empresarial, sindical ou associativa, de preferência, endógena.

De tão relevante, pode vir a constituir uma argumentação circular com o resultado do APL: ele se desenvolve porque tem Governança e a evidência de falta de Governança é o insucesso do APL, relegando a incidência de variáveis estratégicas externas (mercado, competitividade, custos fora dos limites do APL e novas tecnologias).

\section{Rede}

Estudando os trabalhos que usaram as Teorias de Rede para entender APL, (FERNANDES et al., 2009; MARTELETO, 2007; TRES; CANDIDO, 2010; OLIVEIRA et al., 2010; VILGA et al., 2007; QUANDT, 2012; SACOMANO et al., 2015; SILVA et al., 2017; SUGAHARA et al., 2011; BAPTISTA, ALVAREZ, 2007; LOPES et al., 2011; REIS; AMATO NETO, 2011; SARACENI et al., 2013; TEIXEIRA, 2011; COSTA et al., 2018; COSTA et al., 2016; CAMARA, 2008), percebe-se a valorização de alguns pontos: (i) redes são aceitas como um elemento estrutural que, ao mesmo tempo, limita ações e disponibiliza recursos; (ii) redes densas e coesas têm poder dissuasivo sobre o comportamento oportunista ao conferir valor a reputação, tornando menos arriscado agir confiando em reciprocidade de outro agente; (iii) contudo, redes densas, voltadas para si, dispensam pouca atenção às ligações externas, tornando-se menos susceptíveis de adquirir informações não redundantes e, portanto, de maior valor para a inovação; e (iv) dependendo da morfologia da rede, alguns elementos, gozando de uma posição estratégica (por exemplo, como pontes entre atores ou grupos de atores, que na falta dela, estariam desconexos) podem amealhar prestígio, poder, influência e mesmo receber recursos mais tangíveis pela intermediação.

\section{Inovação}

A inovação, no Corpus, é tida como elemento-chave para a competitividade, lucratividade e produtividade dos APL. A busca por modernização, a incorporação de novas tecnologias, processos, matérias-primas e fornecedores e o lançamento de novos produtos desenvolvidos através de investimentos em $P \& D$ parecem restritos a algumas empresas de 
médio e grande porte, dentro da realidade dos APL. Nas micro e pequenas empresas, a inovação é comumente associada à compra de máquinas, mesmo aquelas que são alvos de programas e políticas públicas.

Quanto às fontes de fomento à inovação, percebe-se a dependência de financiamentos governamentais, fazendo-se necessário o fortalecimento de sistemas locais de inovação, a partir das vocações regionais. Há ainda outro expoente: a inovação social. Essa é pouco discutida nos trabalhos sobre APL, mas se mostra promissora em pesquisas futuras.

\section{Política pública}

Há pontos de vista conflitantes. Alguns trabalhos afiançam que a disponibilidade de recursos financeiros por parte dos governos estaduais, devidamente prevista em lei, foi fundamental para o surgimento, estruturação e desenvolvimento do APL, dando suporte, inclusive, para a exportação. Outras pesquisas, enxergam a participação governamental limitada, prescrevendo o aperfeiçoamento das políticas públicas para reduzir a tributação elevada e a fiscalização intensiva e burocrática.

\section{Fatores para o sucesso e insucesso}

Sem pretensão de esgotar as proposições e apenas de forma qualitativa, foram encontradas razões individuais ou combinadas que explicariam o sucesso/fracasso de APL.

Entre os fatores para o sucesso, destacam-se: o estabelecimento de relações de diversas naturezas e de vínculos intensos dentro e fora do APL (AZEVEDO; PARDINI; SIMÃO, 2015), a implementação de ações coletivas (compras, transporte, feiras) (DELALIBERA et al., 2013); a construção de capital social (MOUTINHO; CAMPOS, 2007); o aperfeiçoamento da governança (AZEVEDO FILHO; RIBEIRO, 2011); a ampliação da cooperação/coopetição (ICHIKAWA; SILVA, 2005); o favorecimento da troca de informações (BARBOSA et al., 2008); a identificação social (CALDAS et al., 2007); o aumento da visibilidade da região (DEMICHEI et al., 2015); bons níveis de confiança e de relacionamento (BATALHA et al., 2009); a habituação de tomada de decisão coletiva e aberta (CARLOS FILHO et al., 2015); as “performances inovativas”(CAVALCANTI FILHO; MOUTINHO, 2007); o acesso a financiamento (CABRERA et al., 2017); a capacidade de buscar novas tecnologias (BETIM et al., 2014) e a "ação empreendedora" (CAMPOS; CARVALHO, 2005).

Do lado oposto, em denegação aos fatores de sucesso, portanto, explicando o fracasso (APL pouco desenvolvido, mesmo quando havia possibilidade de melhor resultado), estão: posturas individualistas e introspectivas fomentadas pelos elevados níveis de desconfiança 
(LIBERATO, 2016); baixo nível de cooperação (BRABO et al., 2017); falta de conhecimento técnico (GARCIA; SCUR, 2016); falta de confiança e excesso de conflitos (VILELA; PINTO, 2009 ); oportunismo (OURO FILHO et al., 2015 ); carência de mão-de-obra qualificada (SCHLEMPER et al., 2014), efeitos da assimetria de porte dos empreendimentos (PEREIRA; CAMPOS, 2009); descontinuidade político-administrativa e/ou intervenção isolada e/ou ausência da atuação dos poderes públicos (PASSOS et al., 2004); concorrência desleal (GEREMIA et al., 2015); despreparo para atuação em conjunto (FRANCO; KRETZER, 2008); e falta de fonte de investimentos (FELIX et al., 2018).

\section{DESCRIÇÃO, MODELAGEM E INTEGRAÇÃO}

A Figura 5 traz uma representação (modelo) abarcando as principais variáveis e atributos, agrupados em fatores (em amarelo); construtos, tais como estrutura, agência, governança, confiança, necessidade, cooperação, performance, imagem (em branco); e indicadores de sucesso/insucesso (em azul).

Este modelo se baseia na leitura dos 325 artigos do Corpus e de forma indutiva foi se buscando elementos em comum para uma representação genérica da dinâmica dos APLs, podendo ser utilizada como auxílio para futuras observações do mesmo objeto. A maior parte das pesquisas analisadas é descritiva: esses trabalhos listavam características importantes que foram absorvidas, como elementos singulares (por exemplo: "Subjetividade; Comprometimento; Habitus; Necessidades sociais; Teorias de ação; Altruísmo”); ou com algum grau de agregação bem direta: “Atributos demográficos; Atributos socioeconômicos”.

Esses elementos foram agregados (ou agregados novamente) no modelo. A agregação foi o processo (subjetivo) de trazer para mais próximo, dentro de um construto maior elementos entendidos como associados que compartilhariam características em comum (por exemplo: "Fatores da ordem do indivíduo") e de afastar para outras classes elementos entendidos como de menor grau de proximidade (por exemplo, concentração geográfica não seria um dos fatores da ordem do indivíduo) - seguindo um método próximo da Taxonomia.

Enquanto a agregação pode ser mediada por técnicas estatísticas em trabalhos quantitativos (por exemplo, correlação), a presente análise teve de confiar no cruzamento de considerações subjetivas individuais de cada analista.

As relações entre as categorias emergiram dos trabalhos explicativos do texto, que procuram estabelecer relações de casualidade. Admitidamente, a complexidade da realidade é algumas ordens de grandeza superior ao Modelo que, como tal, é uma redução com o propósito 
de torná-la mais compreensível (haveria argumentos razoáveis demostrando que todos os elementos estão de alguma forma relacionados entre si), daí o destaque das linhas de união entre os construtos, concedido pelos próprios autores do Corpus que as usaram em seus estudos (explicitamente, ou pelo entendimento dos autores da presente pesquisa).

Figura 5 - Modelo resultante da apreensão das proposições do Corpus.

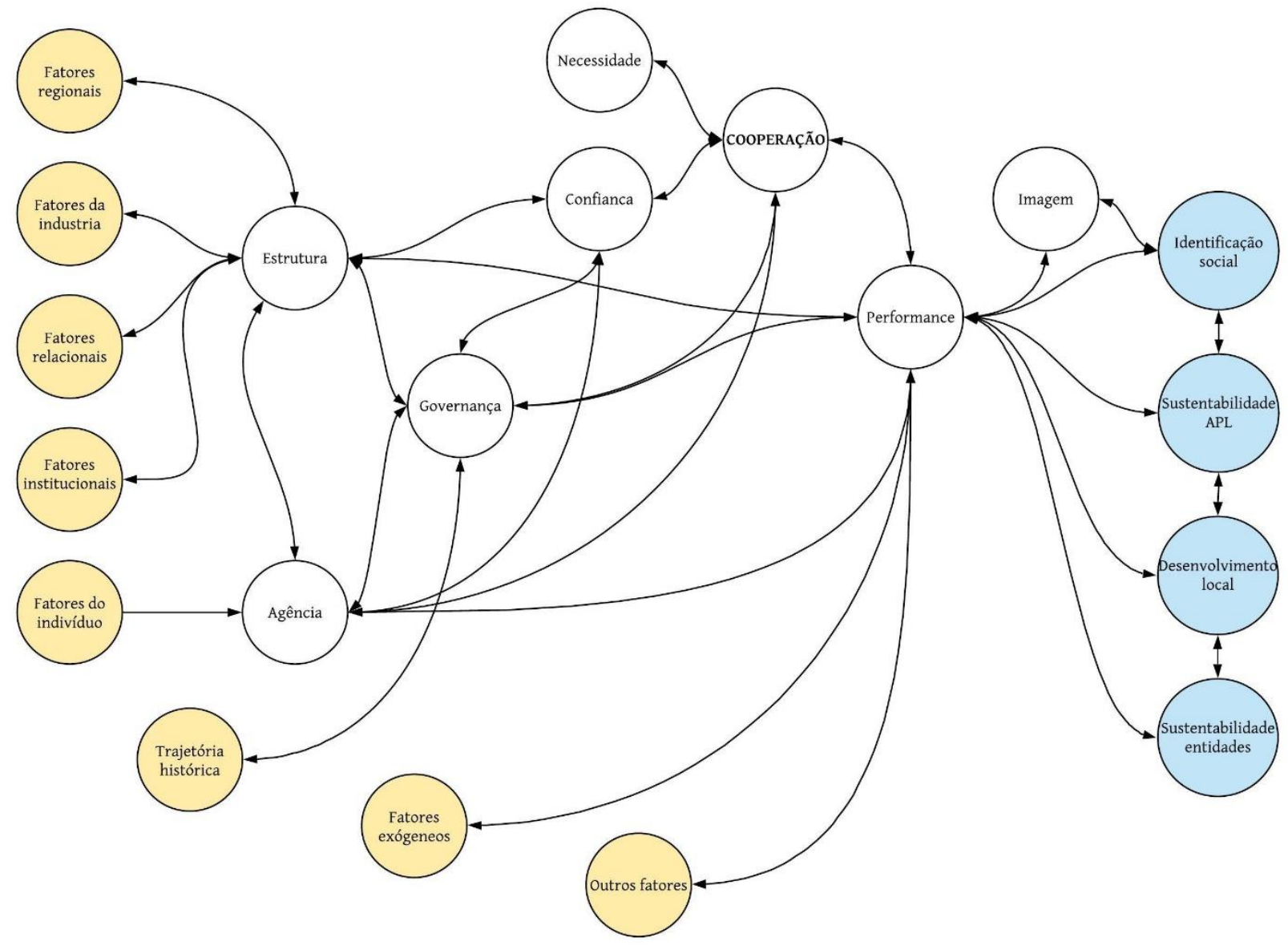

Onde:

Fatores regionais: Renda; Distribuição de renda; Infraestrutura (incluindo educacional); Diversidade econômica; Localização geográfica; Disponibilidade fatores de produção;

Fatores da indústria: Produto; Mercado; Especialização; Interdependência; Diferenciação; Externalidades; Sinergia e complementariedade; Similaridades; Assimetrias; Tecnologia \& processos; Escala e economias de escala; Concentração geográfica; Concentração setorial; Verticalização; Distribuição de recursos; Rivalidade; Especificidades, Barreiras à entrada; e Barreiras à saída. 
Fatores relacionais: Número de vértices; Intensidade das trocas; Frequência das trocas; Diversidade (modos) das trocas; Densidade; Coesão; Centralização; Proximidade; Intermediação, e Fragmentação.

Fatores institucionais: Valores; Crenças; Cultura; Propensão ao oportunismo; Arcabouço legal; Eficiência jurisdicional; Políticas públicas; Mecanismos de financiamento.

Fatores da ordem do indivíduo: Subjetividade; Comprometimento; Habitus; Necessidades sociais; Teorias de ação; Altruísmo; Atributos demográficos; e Atributos socioeconômicos

Governança: Conciliação de interesses; Articulação; Comunicação; Mobilização de recursos; Contratos, Instrumentos coercitivos; Gestão de conflitos; Medição de desempenho; Inclusão \& Exclusão, e Representação.

Trajetória histórica: Nucleação/dissolução; Crescimento; Estabilização; e Declínio.

Cooperação (ações coletivas): Atuação política; Lobby; Práticas sociais; Acordos comerciais; Convênios formais; Freiras; Compras coletivas; Fluxo de informações e de conhecimento; Compartilhamento de recursos; Intercâmbio; Reciprocidade; Escambo; e Market-place comum.

A construção da Figura 5 é uma entre várias possíveis, mas suficiente e mínima para a compreensão da dinâmica de um APL. Aplicando-a, a título de exemplo: “A sustentabilidade do APL e de suas entidades constitutivas decorre da performance e da imagem projetada pelo arranjo, a menos de fatores exógenos. Performance e imagem dependem de ações cooperadas, que são favorecidas quando são necessárias, em uma situação de confiança, governança eficaz, a depender da agência dos participantes. A instituição da confiança depende também da governança sobre uma estrutura favorável (função de vários fatores), e do papel da agência, encontrada em relação dual com a estrutura”. Essa cadeia de casualidade sofre uma escalada de complexidade ao assumir o caráter duplo das relações: a consequência é causa de nova consequência à montante e a jusante, nos ciclos das interações. Exemplificando: esforços cooperados dependem da confiança que é tanto maior quanto maior for a frequência de esforços cooperados, induzindo valor a reputação que reprime a tendência do oportunismo. Por fim, cabe ainda o reparo que as linhas representativas das relações na Figura 5 estão limitadas para efeito de visualização: elas ligariam a maioria dos fatores e suas variáveis entre si.

\section{CONSIDERAÇÕES FINAIS}


APL é objeto complexo, com diversas variáveis, atributos, fatores e construtos intervenientes interrelacionados (mais de cinco dezenas). Mesmo a mera descrição, como empreendida na maioria das pesquisas, exige a incidência de diversas óticas. Na Figura 5 estão presentes elementos caros das teorias: institucionalismo, de custo de transações, econômica industrial, estruturação, de desenvolvimento regional e mesmo de evolucionismo. Quando há ainda pretensões explicativas, de cadeia de casualidade, a complexidade é ainda mais evidente.

Da complexidade, origina-se a maior lacuna: falta de integração. Depois de centenas de pesquisas, não há ainda (e talvez, não haverá em tempo próximo) uma consolidação, que alcance o conjunto - que não seja a Figura 5 - mas algo assemelhado, capaz de oferecer um modelo à compreensão e a testes de integridade.

Para esse efeito e considerando improvável a conjuminação das competências teóricas e instrumentais (estatística, modelagem matemática, sociometria) em uma pessoa, o esforço requer uma equipe multidisciplinar talentosa e recursos, inclusive, de tempo, nem sempre disponíveis quando os trabalhos mais aprofundados são produtos de uma dissertação ou tese, como encontrado no Corpus.

Sendo assim, entende-se que a principal contribuição dessa pesquisa está no âmbito teórico, representada pelo Modelo da Figura 5. Como notas pessoais, acreditamos que o Modelo representa de forma razoável, a pesquisa brasileira em APL e, assim, eventuais lacunas e complementos podem ser apreendidos e estimular novos trabalhos para conhecimento desse arranjo, que parece importante como instrumento de desenvolvimento regional. Tem-se o mapeamento das variáveis, atributos, fatores, construtos e interações, intervenientes na dinâmica do objeto, sinalizando para a falta de integração do conhecimento gerado pelas pesquisas, capaz de oferecer um modelo mais completo ao entendimento.

É válido ressaltar algumas limitações do estudo. A primeira delas é que foi utilizada apenas uma base de dados, o Google Scholar, e a segunda, é quanto ao recorte de estudos utilizando os descritores "arranjos produtivos locais", "arranjo produtivo local” e "aglomeração produtiva local". Além da demonstração do encontrado sobre o objeto nesta amostra analisada na pesquisa e evidenciadas as lacunas encontradas, sugere-se ainda para futuras pesquisas ampliar a base de dados e também o uso do termo de pesquisa; usando o recorte dos últimos cinco anos, a fim de trazer maior volume de contribuições recentes; bem como a utilização de outras técnicas de revisão de literatura.

\section{REFERÊNCIAS}


ALBINO, A. A.; SOUZA, S. D. C.; LIMA, A. T. F. C.; ALMEIDA, M. I. S.; BEHR, R. R. Aplicação do modelo analítico da cadeia de valor na análise da estratificação competitiva em um APL. Revista Produção Online, v. 11, n. 1, p. 263-287, 2011.

ALDRICH, H.E.; PFEFFER, J. Environments of Organizations. Annual Review of Sociology Vol. 2:79-105, 1976.

APLs Brasileiros. Observatório Brasileiro APL. 2018. Disponível em: <http://www.observatorioapl.gov.br/> Acesso em: 25 de jun. de 2019.

ARAÚJO, U. P.; BRITO, M. J.; RIBEIRO, L. M. P; LOPES, F. T. Metainterpretação: Quinze anos de pesquisa com o Relatório da Administração. Revista Contabilidade \& Finanças, v. 27, n. 71, p. 217-231, 2016.

ARAÚJO, U. P.; CORREIA, L. F.; BRITO, M. J.; AMARAL, H. F. Dinâmica da assimilação de métodos analíticos pela ciência no Brasil. REAd-Revista Eletrônica de Administração, v. 22, n. 2, p. 307-332, 2016.

ARAÚJO, U. P.; MENDES, M. L.; GOMES, P. A.; COELHO, S. C. P.; VINÍCIUS, W.; BRITO, M. J. Trajetória e estado corrente da sociometria brasileira. Redes. Revista hispana para el análisis de redes sociales, v. 28, n. 2, p. 97-128, 2017.

AZEVEDO, Ana Cláudia; PARDINI, Daniel Jardim; SIMÃO, Gustavo Leonardo. Capital Social e Relacionamentos Inter E Intrarregionais Em Arranjos Produtivos Locais: Estudo No Apl Calçadista De Nova Serrana/ MG. Revista de Empreendedorismo e Gestão de Pequenas Empresas, v.4, n.2, 2015.

AZEVEDO FILHO, E. T; RIBEIRO, A. C. A governança em aglomerações produtivas: uma análise sobre o setor cerâmico de Campos dos Goytacazes. G\&DR. v. 7, n. 1, p. 96-129, Taubaté, SP, jan-abr/2011.

BARNEY, J. B.; HANSEN, M. H. Trustworthiness as a source of competitive advantage. Strategic Management Journal, Winter Special Issue, v. 15, p. 175-190, 1994.

BAPTISTA, Josil do Rocio Voidela; ALVAREZ, Victor Manoel Pelaez. Relações Socioeconômicas em Rede: a governança no Arranjo Produtivo do Vestuário de cianorte no estado do Paraná. Revista Paranaense de Desenvolvimento, Curitiba, n.113, p.59-81, jul./dez. 2007.

BARBOSA, T. A. C; SOUZA, J. V; OLIVA, E. C. O Serviço de Atendimento ao Consumidor como agente de mudanças nas indústrias do Pólo de Cosméticos de Diadema. Rev. FAE, Curitiba, v.11, n.1, p.33-42, jan./jun. 2008.

BATALHA, M. O; DE MORI, C; ALVES FILHO, A. G. Abordagens espaço-relacional de organização da produção em estudos de atividades de produção agroindustrial no Brasil.

Revista Brasileira de Gestão e Desenvolvimento Regional. v. 5, n. 3, p. 94-115, Taubaté, SP, set-dez/2009.

BARDIN, L. Análise de conteúdo. 3 ed. Lisboa: Edições 70, 2004. 
BETIM, L. M; RESENDE, L. M; ANDRADE JUNIOR, P. P; AGNER, T. V. Análise d o nível de produtividade e competitividade em aglomerado produtivo de empresas. Espacios, vol. 35, no 4, p. 19, 2014.

BORGATti, S. P., EVERETT, M. G., JOHNSON, J. C. Analyzing social networks. Sage, 2013.

BRABO, M. F; PAIXÃO, D. J. M.; COSTA, M. W. M.; SILVA, G. A.; CAMPELO, D. A. V; VERAS, G. C. Arranjo Produtivo Local da Piscicultura na Região de Capitão Poço/PA: Bases para a Consolidação. Rev. Bras. Eng. Pesca. Vol 10: 27-40, 2017.

BRANNAN, M. J.; FLEETWOOD, S.; O'MAHONEY, J.; VINCENT, S. Critical Essay: Meta-analysis: A critical realist critique and alternative. Human Relations, v. 70, n. 1, p. 1139, 2017.

BURT, R. S. Structural Holes: The Social Structure of Competition, Cambridge, MA, Harvard Univ. Press, 1992.

CABRERA, L. C; SCHULTZ, G; TALAMINI, E. Limites e oportunidades para a construção de um Arranjo Produtivo Local (APL): a experiência do projeto Balde Cheio em Mato Grosso do Sul. Interações, Campo Grande, MS, v. 18, n. 4, p. 19-10, out./dez. 2017.

CALDAS, A; ALMEIDA, A. LEAL, D. MACHADO, V. Tecnologia social: cooperação universidade/comunidade para o desenvolvimento urbano regional e local sustentável. RDE Revista de Desenvolvimento Econômico, Ano IX, Nº 16, Salvador, BA. Dezembro de 2007.

CAMARA, Marcia Regina Gabardo da; et al. Cadeia têxtil-vestuário: Discutindo a existência de um Arranjo produtivo local na Região metropolitana de Londrina-paraná. Alcance UNIVALI - Vol. 15 - n.1 p. 103 - 121 - Jan / Abr 2008.

CAMPOS, K. C; CARVALHO, F. M. A. Arranjos Produtivos Locais: a atuação dos atores e dos programas municipais. Economia-Ensaios, Uberlândia, 20(1): 65-80, dez./2005.

CARLOS FILHO, F. A; LAGIOIA, U. C. T; DE ARAÚJO, J. G. N; SILVA FILHO, L. L; BARBOSA, I. S. Gestão do Risco Operacional em Arranjo Produtivo Local: Um Estudo Exploratório no Setor de Fruticultura. Revista Catarinense da Ciência Contábil - CRCSC, Florianópolis, v. 14, n. 41, p. 46-60, jan./abr. 2015.

CASAROTTO FILHO, N.; PIRES, L. H. Redes de pequenas e médias empresas e desenvolvimento local. São Paulo: Atlas, 2001.

CASSIOLATO, J. E.; LASTRES, H. MM. Arranjos e sistemas produtivos locais na indústria brasileira. Revista de economia contemporânea, v. 5, n. 3, 2001.

CASSIOLATO, J. E.; LASTRES, H. MM. O foco em arranjos produtivos e inovativos locais de micro e pequenas empresas. Pequena empresa: cooperação e desenvolvimento local. Rio de Janeiro: Relume Dumará, p. 21-34, 2003.

CASTELLS, M. A sociedade em rede. A era da Informação: Economia. Sociedade e Cultura, v. 1, p. 5, 1999. 
CAVALCANTI FILHO, P. F; MOUTINHO, L. M. G. Cooperação Institucional como Estratégia Inovativa: O Caso do APL de Confecções em Campina Grande. Revista Econ. contemporânea, Rio de Janeiro, v. 11, n. 3, p. 475-507, set./dez. 2007.

COHEN, S. Symbols of trouble. In Gelder, K\& Thornton, S. (1998), The subcultures Reader. London: Routledge, 1980.

COSTA, Esdras da Silva; et al. Análise das relações e ações conjuntas entre as empresas do APL têxtil da região metropolitana de São Paulo: contribuições para o seu crescimento. Interações (Campo Grande) vol.19 no.2 Campo Grande Apr./June 2018.

COSTA, Rodrigo Souza; DA SILVA, Eduardo Damião; NOGUEIRA, Danillo Prado. Ações de cooperação, aprendizagem e Estratégias organizacionais em redes Interorganizacionais: estudo nos arranjos produtivos locais (APL) de software do Paraná. Revista Eletrônica de Ciência Administrativa, Curitiba - PR, v. 15, n. 3, p. 189-208, Set-Dez 2016.

DELALIBERA, P. H. A; LIMA, R. S; TURRIONI, J. B. Pesquisa levantamento para análise do modelo de compras conjuntas adotado em arranjos produtivos locais de Minas Gerais. Production. Itajubá, MG. 2013.

DEMICHEI, A. L; DE MERA, C. M. P; DIVERIO, T. S. M. O Desenvolvimento de um Setor Metal-Mecânico no Rio Grande Do Sul, Região do Alto Jacuí: Origem e Consequências. Revista gestão e desenvolvimento em contexto- GEDECON. vol.3, nº. 02, 2015.

DEMSETZ, H. Industrial structure, market rivality and politic policy. Journal of Law Economic Organization, v. 16, p. 1-10, 1973.

DENZIN, Norman K. Problems in Analyzing Elements of Mass Culture: Notes on the Popular Song and Other Artistic Productions. American Journal of Sociology. Volume 75, Number 6, Maio 1970.

DIMAGGIO, P. J.; POWELL, W. W. The iron cage revisited: Institutional isomorphism and collective rationality in organizational fields. American sociological review, p. 147-160, 1983.

FARAH JÚNIOR, M. F. Desenvolvimento Local e Comportamento dos Agentes Econômicos: Estratégias Empresariais Pró-ativas ou Reativas? Revista da FAE, v. 4, n. 2, 2001.

FISCHER R. e W. URY. Getting to Yes: How to Negociate without giving in. Londres: Arrow Books, 1981.

FELIX, M. Z. M; COELHO, C. S; NEVES, S. D. Desenvolvimento de um arranjo produtivo de confecção de artigos de couro na cidade de Serrita. Revista Semiárido De Visu, Petrolina, v. 6, n. 1, p. $32-42,2018$.

FERNANDES, Karoline; LOURENÇO, Francisneide; LOURENÇO, José Nestor. Identificação, caracterização e inserção no mercado de produtos orgânicos na região da Barreira do Andirá. Rev. Bras. de Agroecologia, v. 4, n.2, nov. 2009. 
FLICK, Uwe. Uma introdução à pesquisa qualitativa. 3. Ed. Porto Alegre: Bookman, 2008.

FOSS, J. N. The resource-based perspective: an assessment and diagnosis of problems. DRUID Working Paper N. 97-1. Copenhagen: Copenhagen Business School, 1997, p. 1-3 1993.

FRANCO, G. L; KRETZER, J. Micro e pequenas empresas em arranjos produtivos Locais: um estudo de caso do aglomerado de Confecção - bordado infantil em terra roxa/PR. Revista Capital Científico. Guarapuava - PR v.6 n.1 p.33-63 jan./dez. 2008.

GARCIA, R. SCUR, G. Ciclo de vida do cluster e a evolução das capacitações das empresas: uma análise do sistema local de cerâmica de revestimento de Santa Gertrudes. Revista Pymes, Innovación y Desarrollo. Vol. 4, No.1, pp. 95-114, 2016.

GEREMIA, F; MEDEIROS, A. P; QUEDI, R. C; GEREMIA, R. Inserção competitiva da indústria do mobiliário: estudo de caso a partir do referencial de arranjos produtivos locais. Informe Gepec, Toledo, v. 19, n. 1, p. 80-96, jan./jun. 2015.

GIL, A. C. Como elaborar projetos de pesquisa. 4. Ed. São Paulo: Atlas, 2002.

GRANOVETTER, M. The strength of weak ties: a network theory revisited. In: Sociological Theory. Ed. Randall Collins. San Franciso, Califórnia, série Jossey-Bass, v.1. p. 2001-2233, 1983.

GUION, Robert M. Validity and reliability. In S. G. Rogelberg (Ed.), Handbook of research methods in industrial and organizational psychology, p. 57-76, Malden, MA: Blackwell, 2002.

HOON, C.. Meta-synthesis of qualitative case studies: An approach to theory building. Organizational Research Methods, v. 16, n. 4, p. 522-556, 2013.

ICHIKAWA, R. A. e SILVA, R. S. Arranjos produtivos locais: uma alternativa de empreendimento rumo ao desenvolvimento sustentável. Caderno De Administração. V. 13, N.2, p.13-23, JUL/DEZ. 2005.

LASTRES, H.M.M.; CASSIOLATO, J.E. Glossário de arranjos e sistemas produtivos e inovativos locais: redes de pesquisas em sistemas produtivos e inovativos locais - Redesist. Instituto de Economia da Universidade Federal do Rio de Janeiro - IE/UFRJ, 2003.

LIBERATO, J. S; Mudança da monocultura do fumo no agreste alagoano: seus arranjos produtivos locais e os impactos na estrutura social. International Journal of Professional Business Review (JBReview), São Paulo V.1 N.2, pp.66-75, Jul/Dez, 2016.

LUNDVALL, B. Why study national sytems and national styles of innovation. Technology analysis \& strategic management, v. 10, p. 407-421, 1998.

LOPES, Brenner; MUYLDER,Cristina Fernandes; JUDICE, Valéria Maria Martins. Inteligência competitiva e o caso de um arranjo produtivo local de eletrônica brasileiro. Revista Gestão e Planejamento, Salvador, v. 12, n. 2, p. 213-231, jul./dez. 2011. 
MACHADO-DA-SILVA, C. L.; FONSECA, V. S. da. Competitividade organizacional: uma tentativa de reconstrução analítica. Organizações \& Sociedade, 4(7), 97- 114, 1996.

MARSHALL, A. Princípios de economia: tratado introdutório. Vol. I. $2^{\text {a }}$ ed., São Paulo: Nova Cultural, 1985. (Col. Os Economistas).

MARTELETO, Regina Maria. Teoria e metodologia de redes sociais nos Estudos da informação: cruzamentos Interdisciplinares. Inf. Inf., Londrina, V. 12, n. esp., 2007.

MASCENA, K. M. C.; FIGUEIREDO, F. C.; BOAVENTURA, J. M. G. Clusters e APL's: Análise bibliométrica das publicações nacionais no período de 2000 a 2011 . RAE-revista de administração de empresas, v. 53, n. 5, p. 454-468, 2013.

MILLS, H.A. Negociação: a arte de vencer. São Paulo: Makron Books, 1993.

MOUTINHO, L. M. G; CAMPOS, Renato. A Co-Evolução de Empresas e Instituições em Arranjos Produtivos Locais: Políticas Públicas e Sustentabilidade. Revista Econômica do Nordeste, Fortaleza, v. 38, nº 2, abr-jun. 2007.

NELSON, R., WINTER, S.. In search of a usefui theory of innovation. Research Policy, v.5, p.36-78, 1977.

NETO, J. A. Redes de cooperação produtiva e clusters regionais: oportunidades para as pequenas e médias empresas. Editora Atlas, 2000.

NOOY, W.; MRVAR, A.; BATAGELJ, V. Exploratory social network analysis with Pajek: Revised and expanded edition for updated software. Cambridge University Press, 2011.

OLIVEIRA, C. L.C; LAURINDO, F. J. B; NETO, J.A; CHINEN, C. M. Cadeia de valor do Pré-sal: criando valor através da Internet. Prisma.Com n. ${ }^{\circ}$ 13, 2010.

OURO, Abimael; BARRETO, Ikaro. Um Estudo Bibliométrico Sobre Arranjo Produtivo Local. Cadernos de Gestão e Empreendedorismo. v .2. n.1. p 32-50. Jan-Abril. 2014.

OURO FILHO, A. M; OLAVE, M. E. L; BARRETO, I. D. C. Fatores Desarticuladores da Cooperação em Arranjos Produtivos Locais: Um Estudo Quantitativo no APL de Confecções de Tobias Barreto/SE. Brazilian Business Review, Vitória RS, v. 12, n. 5, Art. 2, p. 17 - 40, set.-out. 2015.

OKUBO, Yoshiko. Bibliometric indicators and analysis of research systems: methods and examples. 1997.

PASSOS, Francisco Uchoa, et al. Capacidade inovativa e demandas tecnológicas de Arranjos Produtivos Locais: um Estudo de caso do APL de flores em Maracás, Bahia. Revista

Desenbahia. V. 1, n. 1, set. 2004.

PENROSE, E. The theory of the growth of the firm. Oxford: Basil Blackwell, 1959. 
PEREIRA, J. R; CAMPOS, A. L. A. Polos Produtivos Locais: A Indústria Moveleira de Linhares. Pesquisa em Debate, edição especial, 2009.

PIRES, L. H. Redes de pequenas e médias empresas e desenvolvimento local. São Paulo: Atlas, 1999.

PORTER, M. E.; GOLEMAN, D.; SHAPIRO, C.; VARIAN, H. R.; FRIEDMAN, S. D.; CHRISTENSEN, PERRY; et al. Clusters and the new economics of competition. Boston: Harvard Business Review, 1998.

PORTER, M. A vantagem competitiva das nações. Rio de Janeiro: Campus, 1993.

QUANDT, Carlos Olavo. Redes De Cooperação E Inovação Localizada: Estudo De Caso De Um Arranjo Produtivo Local. Revista de Administração e Inovação, São Paulo, v. 9, n. 1, p.141-166, jan./mar. 2012.

REIS, Ana Paula; AMATO NETO, João. Aprendizagem por cooperação em rede: práticas de conhecimento em arranjos produtivos locais de software. Produção, V. 20, n. 10, 2011.

ROGERS, E. Diffusion of innovations. New York: The Free Press, 1983.

ROSSETTO, C. R.; ROSSETTO, A. M. Teoria institucional e dependência de recursos na adaptação organizacional: uma visão complementar. RAE-eletrônica, v. 4, n. 1, 2005.

SACOMANO, M. N; CORRÊA, D. A; TRUZZI, O. M. S. Transferência de Conhecimento em Redes de Empresas: Um Estudo em uma Planta Modular da Indústria Automotiva. E\&G Economia e Gestão, Belo Horizonte, v. 15, n. 41, Out./Dez. 2015.

SANTOS, I. S.; PARISOTO, G. J.; GIL, S. O; SCHULTZ, G. Arranjos Produtivos Locais: Análise Bibliométrica das Publicações de Artigos nos Últimos dez anos. Desenvolvimento Regional: Processos, Políticas e Transformações Territoriais. Santa Cruz do Sul, RS. 2019.

SARACENI, Adriana Valéria; ANDRADE JÚNIOR, Pedro Paulo de; RESENDE, Luis Mauricio. Gestão de conhecimento em aglomerados de empresas: rede de valor como Instrumento para fortalecer o intercâmbio de conhecimento. Estratégia \& Negócios. Florianópolis, v.6, n.1, p. 89-107, jan./abr. 2013.

SCHLEMPER, A. L; MARINI, M. J. BERNARTT, M. L. Ensino e Formação Profissional como Suporte aos Arranjos Produtivos Locais da Região Sudoeste do Paraná.

Desenvolvimento em Questão. Editora Unijuí. Ano 12, n. 27, jul./set. 2014.

SCHERER, F.; ROSS, D. Market structure and economic performance. Boston: Houghon Mifflin, 1990.

SCHUMPETER, J. Teoria do Desenvolvimento Econômico. São Paulo: Abril Cultural, 1988.

SCOTT, W. R. Institutions and organizations. 1. ed. Thousand Oaks: Sage, 1995a.

SILVA, Anderson Diego Farias; FERNANDES, Nelson da Cruz Monteiro; PAIVA, Fernando. O Estudo de Caso Naturalista na investigação de Arranjos Produtivos Locais

(c) $($ (1) $\Theta$ REAd | Porto Alegre - Vol. 26 - ‥ 3 - Setembro / Dezembro 2020 - p. 709-738. 
(APL) de Tecnologias de Informação e Comunicação (TIC). Journal of Perspectives in Management - JPM, 1(1), p. 36-50, 2017.

STAKE, R. E. Pesquisa qualitative: estudando como as coisas funcionam. Porto Alegre: Penso, 2011.

SUGAHARA, Cibele Roberta; VERGUEIRO, Waldomiro de Castro Santos. Redes sociais: um olhar sobre a dinâmica da informação na rede (APL) Arranjo Produtivo Local Têxtil, de Americana - São Paulo. Rev. Interam. Bibliot. Medellín (Colombia) Vol. 34, n 2, pp. 177 $186,2011$.

SUZIGAN, Wilson; FURTADO, João; GARCIA, Renato; SAMPAIO, Sérgio. Clusters ou sistemas locais de produção: mapeamento, tipologia e sugestões de políticas. Revista de Economia Política, v. 24, n. 4, p. 543-562, 2004.

TEIXEIRA, F.; FERRARO, C. A. Aglomeraciones productivas locales en Brasil, formación de recursos humanos y resultados de la experiencia CEPAL-SEBRAE. Cepal, 2009.

TEIXEIRA, Marcia Cristina; TEIXEIRA, Rivanda Meira. Relacionamento, cooperação e governança em arranjos Produtivos locais: o caso do apl de madeira e móveis do estado De Rondônia. REAd - Edição 68, Volume 17, Nº 1, jan/abr, p. 237-269, 2011.

TRÊS, Douglas Luis; CÂNDIDO, Marcondes da Silva. Sistema inteligência setorial: acesso e compartilhamento de informação e conhecimento para a obtenção de vantagem competitiva. REBRAE. Revista Brasileira de Estratégia, Curitiba, v. 3, n. 3, p. 245-252, set./dez. 2010.

VILELA, L. E. PINTO, M. C. S. Governança e gestão social em redes empresariais: análise de três arranjos produtivos locais (APLs) de confecções no estado do Rio de Janeiro. RAP Rio de Janeiro 43(5):1067-1089, Set./out. 2009.

VILGA, V. F; FARAH, O. E; SACOMANO NETO, M; GIULIANI, A. C. Vantagens competitivas em redes de micro, pequena e média empresas, o caso da Rede Brasil Escolar.

Revista Gerenciais, São Paulo, v. 6, n. 1, p. 23-33, 2007.

WILLIAMSON, Oliver E. The firm as a nexus of treaties: an introduction. In: AOKI, M. et al. eds. The firm as a nexus of treaties. London: Sage, 1990. 